\title{
ATENÇÃO FARMACÊUTICA NO TRATAMENTO DE CRIANÇAS INFECTADAS PELO VÍRUS HIV/AIDS
}

\author{
PHARMACEUTICAL CARE IN THE TREATMENT OF CHILDREN INFECTED BY THE \\ HIV/AIDS VIRUS
}

Ana Paula Nogueira da Silva ${ }^{1}$

Vicente Antonio de Senna Junior ${ }^{2}$

RESUMO: Por volta da década de 8o surgiu um vírus que matou milhares de pessoas, o Vírus da Imunodeficiência Adquirida (HIV), responsável pela Síndrome da Imunodeficiência Adquirida (AIDS), tendo como único tratamento para cessar a replicação do vírus o uso de antirretrovirais. A atenção farmacêutica é uma estratégia que tem como princípio ações focadas no bem-estar do paciente. Objetiva-se nessa pesquisa apresentar por meio das ações da atenção farmacêutica os benefícios para o tratamento de crianças portadores do vírus HIV/AIDS. A pesquisa foi realizada por meio da metodologia de revisão de literatura, onde os dados foram apurados por meio de artigos, manuais governamentais e sites relevantes. A revisão disserta sobre a importância da atenção farmacêutica na farmacoterapia com antirretrovirais em crianças com $\mathrm{HIV} / \mathrm{AIDS}$.

Palavras-chave: AIDS. Atenção Farmacêutica. HIV. Terapia Antirretrovital. Pediátrico.

ABSTRACT: Around the 8o's, a virus emerged that killed thousands of people, the Acquired Immunodeficiency Virus (HIV) responsible for the Acquired Immunodeficiency Syndrome (AIDS), with the only treatment to stop the replication of the virus being the use of antiretrovirals. Pharmaceutical care is a strategy whose principles are actions focused on the patient's well-being. The objective of this research is to present, through the actions of pharmaceutical care, the benefits for the treatment of children with the HIV/AIDS virus. The research was conducted through the literature review methodology, where data were collected through articles, government manuals and relevant websites. A review discusses the importance of pharmaceutical care in antiretroviral pharmacotherapy in children with HIV/AIDS.

Keywords: AIDS. Pharmaceutical Attention. HIV. Antiretrovital Therapy. Pediatric.

\footnotetext{
${ }^{1}$ UNIG - Universidade Iguaçu, Curso de Graduação em Farmácia, Nova Iguaçu-RJ, Brasil.

${ }^{2}$ Orientador.
} 


\section{INTRODUÇÃO}

Acredita-se veementemente que a infecção do vírus da imunodeficiência humana (HIV) tenha sido originada no Congo por volta do ano 1920, sendo transmitido à princípio entre os chimpanzés. A propagação entre humanos relata os pesquisadores, pode ter sido através dos caçadores ao ter contato com animais contaminados. A transmissão na África ocorreu lentamente durante muitas décadas, e mais tarde para os demais países. Por volta da década de 80 ainda era pouco conhecido, porém já disseminado em todos os continentes, com uma estimativa que 100.000 a 300.000 pessoas tenham sido infectadas naquela época (THE AIDS INSTITUT, 20II).

Com o avanço da medicina, os estudos têm sido fundamentais para a criação de toxinas e fármacos para conter a evolução e multiplicação desse vírus potencialmente letal, visando a desaceleração da infecção. O sistema imunológico do paciente uma vez afetado, fica suscetível a contrair outras doenças, pois a característica do vírus é a replicação, utilizando componentes dos glóbulos brancos, dessa forma causando deficiência na defesa do indivíduo portador do HIV, sendo assim diagnosticado com a Acquired Immunodeficiency Syndrome (AIDS) (PONTE, 2012).

$\mathrm{O}$ vírus HIV tem um crescimento equiparado com a população mundial, sendo as crianças infectadas através da genética dos pais portadores da síndrome, como também pelo ato sexual em casos de abuso sexual. Os continentes Africano e Asiático lideram os casos de crianças infectadas. Entidades governamentais, órgãos mundiais que visam a qualidade de vida de crianças e jovens adultos como a Organização Mundial da Saúde (OMS) e o Fundo das Nações Unidas para a Infância (UNICEF) estão em constante empenho afim de reduzir os números de novos contágios (TIMERMAN, 2015).

Em consonância com dados da UNAIDS em seu relatório de 2020, cerca de 1,8 milhões de crianças com menos de $\mathrm{I} 4$ anos foram infectadas no mundo. Porém desde 2010, as novas infecções por HIV em crianças caíram 52\%, de 320 mil em 2010 para I6o mil em 2020 (UNAIDS, 2021). 
Os antirretrovirais, geralmente conhecidos como "coquetel", foram descobertos por volta da década de 8o, agem de modo direto na célula infectada, impedindo a replicação do vírus, de modo que o portador tenha uma redução' da carga viral, enfraquecendo a doença. A terapia com antirretrovirais deve ser acompanhada por uma equipe multidisciplinar, enfatizando o papel do farmacêutico que dispensa o fármaco dispondo de uma farmacoterapia de qualidade, tendo como objetivo um tratamento com efeito satisfatório (FERREIRA et. al, 2017).

O tratamento com antirretrovirais é fundamental para controlar a replicação do vírus HIV e proporcionais resultados satisfatórios que são esperados através da atenção farmacêutica. Considerada uma ferramenta do profissional de farmácia, a atenção farmacêutica (ATF) dispõe sobre atitudes, comportamentos, valores éticos, compromissos e responsabilidade na prevenção, promoção, e reabilitação da saúde, na integralidade com a equipe de saúde, objetivando o uso racional do medicamento pelo paciente. $\mathrm{Na}$ contemporaneidade essa ferramenta farmacêutica envolve fatores como: farmacoterapia correta, dispensação de qualidade, intervenção farmacêutica em casos de reações adversas, acompanhamento e o Uso Racional de Medicamentos (URM), auxiliando no tratamento com os antirretrovirais (BRASIL, 20I0; FERREIRA, 2014).

Diante desse exposto, objetiva-se nesse estudo analisar a importância das técnicas de assistência farmacêutica afim de garantir melhor qualidade de vida do usuário pediátrico por meio do contato direto com o profissional de saúde, visando melhor aderência ao tratamento com antirretrovirais, evitando a interrupção e afastamento do mesmo, reforçando a importância do farmacêutico diante da responsabilidade de cuidar dos pacientes com HIV/AIDS.

\section{I. OBJETIVO GERAL}

Demonstrar a importância da assistência farmacêutica na adesão e resposta terapêutica do paciente pediátrico portador do vírus HIV/AIDS, com a finalidade de assegurar a eficácia do tratamento antirretroviral proposto ao paciente e evitar o afastamento da terapia. 


\subsection{OBJETIVOS ESPECÍFICOS}

- Descrever o HIV/AIDS e sua transmissão para as crianças;

- Elucidar sobre a importância da atenção farmacêutica no tratamento;

- Explicar a importância atuação farmacêutica na dispensação de antirretrovirais;

- Promover o uso racional da terapia visando evitar afastamento do tratamento;

- Abordar sobre a terapia antirretroviral no tratamento de crianças com HIV.

\section{MÉTODO}

Para obtenção dos dados dessa pesquisa, foi utilizado método qualitativo, por meio de revisão de literatura, utilizando dados coletados através das bases de dados no per: Google Acadêmico, SciELO - Scientific Eletronic Library, livros, periódicos, monografias, congressos, legislações, dissertações, Ministério da Saúde (MS) que datam do ano de 2000 a 2021. De modo descritivo, como critério de inclusão foram pré-definidos os materiais em língua portuguesa, inglesa e espanhola, artigos que descreviam sobre assistência farmacêutica e aderência ao tratamento. Os critérios de exclusão utilizados foram os artigos fora do período escolhido, os de outras línguas que não foram mencionadas anteriormente e aqueles que não podiam ser lidos na íntegra.

\section{JUSTIFICATIVA}

Justifica-se nesse trabalho elucidar a importância da atenção farmacêutica no tratamento do HIV/AIDS no paciente pediátrico, a fim de promover melhor aderência ao tratamento, promovendo o uso racional da terapia antirretroviral, evitando o abandono do tratamento para proporcionar melhor qualidade de vida às crianças.

\section{REVISÃO DE LITERATURA}

\section{I HIV: O QUE É, COMO OCORRE A TRANSMISSÃO E QUAL TRATAMENTO}

O Vírus da Imunodeficiência Humana (HIV) é o responsável pela Síndrome Da Imunodeficiência Adquirida, habitualmente conhecida por (AIDS), esse vírus ataca 
vagarosamente o sistema imunológico, de forma que as principais células a serem infectadas são os linfócitos $\mathrm{T} \mathrm{CD}_{4}$, linfócitos $\mathrm{CD}_{4}+$ e macrófagos (PEREIRA, 2012).

Quando o HIV invade o sistema imunológico deixa o indivíduo mais predisposto a contrair outras doenças infecciosas, fazendo com que as células produzidas sejam rapidamente destruídas, resultando em um organismo com uma defesa imunológica enfraquecida (VASCONCELOS, 2009).

Para diagnóstico do HIV As estruturas mais relevantes para identificar o vírus são as proteínas do envelope viral (gpi6o, gpizo e gp4I), as estruturas proteicas que tem por codificação o gene pol (p66, p5I, p3i) e as do gene gag (p55, p24 e pi7) (MINISTÉRIO DA SAÚDE, 2013).

FIGURA I: Representação esquemática da estrutura do HIV-I

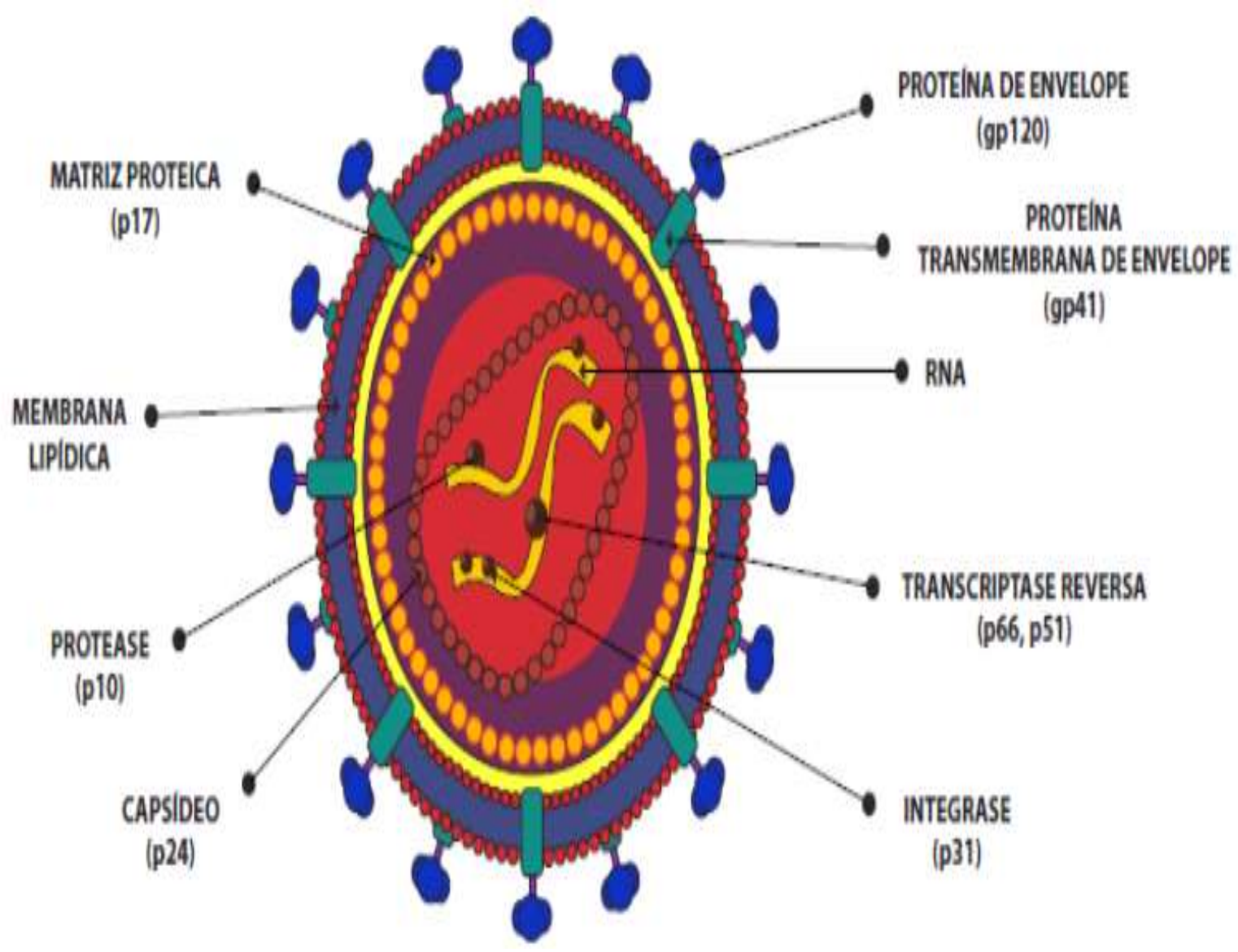

FONTE: MINISTÉRIO DA SAÚDE, 2013 
A transmissão do HIV ocorre através da mãe para o bebê na gravidez, durante o trabalho de parto, onde o bebê tem contato com secreções vaginais e sangue da mãe infectada, e também pelo aleitamento materno. Esse tipo de transmissão vertical ocorre em cerca de $25 \%$ das mães portadoras do vírus, quando as mesmas não realizam a profilaxia através dos antirretrovirais durante a gestação (PEREIRA, 20I2; BRASIL, 2007).

A infecção por HIV não possui cura, porém há tratamento, que desaceleram e inibem a replicação do vírus, conhecido como terapia antirretroviral, também reconhecida pela sigla TARV, sendo imprescindível para manutenção da qualidade de vida, e redução do risco de transmissão para outras pessoas. As drogas utilizadas no tratamento se subdividem em 5 classes: duas inibidores de transcriptase reversa (ITRN e ITRNN), uma de inibidores de protease, uma de inibidor de entrada, e uma de inibidores de integrase. Sendo que as duas últimas contam respectivamente com 2 e $\mathrm{I}$ inibidores aprovados, e inúmeras drogas ainda estão sendo testadas. Alguns exemplos das drogas utilizadas são: Abacavir, Estavudina, Zidovudina, Ratelgravir, Fosampremavir, entre inúmeros outros (OLIVEIROS, 2009).

\subsection{DADOS MUNDIAIS SOBRE A TRANSMISSÃO DO VÍRUS}

De acordo com o relatório produzido pelo UNAIDS (2021), em dezembro de 2020, cerca de 37,6 milhões [30,2 milhões-45 milhões] de pessoas conviviam com o HIV no mundo, destas 35,9 milhões são adultos e 1,7 milhões [1,2 milhões-2,2 milhões] são crianças de até 14 anos.

Dados da FIOCRUZ relatam que da década de 80 até por volta do ano 2012, foram registradas 656.70I infecções por AIDS no Brasil, destas, 230.16ı são mulheres e 12.916 casos de crianças até 13 anos que manifestaram a infecção por intermédio da transmissão vertical. No ano de 202I, segundo relatório da UNAIDS cerca de 2,2 milhões de crianças menores de 14 anos convivem com a doença no mundo. Dessas crianças, pouco mais de 53\% têm acesso à terapia com antirretrovirais. Em 2020 cerca de $84 \%$ das mulheres positivas para HIV, receberam o tratamento antirretroviral e preveniram seus bebês de terem contato com o vírus (FIOCRUZ, 2013; UNAIDS, 202I). 
TABELA I - Dados globais de crianças portadoras do HIV, de o-I4 anos, de 2015 a 2020.

\begin{tabular}{|c|c|}
\hline ANO & $\begin{array}{l}\text { VALORES APROXIMADOS DE NOVAS } \\
\text { INFECÇÕES POR HIV (o A } 14 \text { ANOS) }\end{array}$ \\
\hline 2015 & $190000[120000-280000]$ \\
\hline 2016 & I8o ooo $[110$ ooo -270000$]$ \\
\hline 2017 & I8o ooo $[110$ ooo -260 ooo $]$ \\
\hline 2020 & I6o ooo $[100$ ooo -240000$]$ \\
\hline
\end{tabular}

FONTE: UNAIDS, 202I

\subsection{ATENÇÃO FARMACÊUTICA}

O conceito de atenção farmacêutica (AF) foi definido pela Organização Mundial da Saúde (OMS), em 1993, como uma atividade onde a finalidade principal dos planejamentos e ações do farmacêutico sejam focadas no paciente, refletindo a ética, profissionalismo, responsabilidades, entendimento, decisões estratégicas em cada processo exercido na farmacoterapia, objetivando alcançar soluções e efeitos significativos na terapêutica do paciente proporcionando qualidade de vida do indivíduo e da coletividade (ANGONESI \& SEVALHO, 2010).

A AF é uma efetiva e importante ferramenta que dispõe sobre o auxílio a pacientes portadores de HIV, aperfeiçoando a terapia antirretroviral, propondo ao paciente melhor adesão ao tratamento e ao serviço de saúde, promovendo qualidade de vida e uso racional da terapêutica escolhida. Sendo o uso racional dos medicamentos essenciais para a eficácia e segurança do paciente em tratamento de HIV/AIDS. Demonstrando assim, que o farmacêutico é o profissional mais qualificado para assistir o paciente a respeito da farmacoterapia empregada no tratamento, competindo ao farmacêutico a orientação, esclarecimentos das dúvidas do paciente, contemplando aspectos, riscos e benefícios da TARV (VIELMO et al, 2014; RIBEIRO, 2017).

Por ser uma ferramenta relativamente recente, pois foi implementada depois dos anos 2000, ainda é muito confundida com assistência farmacêutica, sendo necessário a realização de mais estudos, e incentivo dos profissionais para abranger e possibilitar a 
utilização da mesma na atuação do profissional farmacêutico (CAETANO \& NETO, 2017).

\subsection{ATENÇÃO FARMACÊUTICA NO TRATAMENTO DE CRIANÇAS PORTADORAS DO VÍRUS HIV/AIDS}

O crescimento da população pediátrica infectada pelo vírus HIV tem aumentado nos últimos anos, sendo um problema de saúde mundial. A epidemia da AIDS atinge milhares de pessoas, sendo os países subdesenvolvidos os mais afetados. No Brasil da década de 80 até o ano 2015, foram notificados cerca de 799.00o casos de HIV/AIDS, as regiões sul e sudeste lideravam o número de casos da doença (UNAIDS, 2021; ZANON et al, 2016)

A avaliação de mulheres de 15 a 49 anos infectadas por HIV é fundamental para a não transmissão às crianças, visto que $90 \%$ das crianças portadoras do vírus foram infectadas de mãe para bebê no que se caracteriza a transmissão vertical, durante gestação, parto ou amamentação de mães que não fizeram a TARV durante a gestação e/ou não foram orientadas a não amamentar após o parto. As medidas para evitar que as crianças sejam infectadas são: fazer uso de antirretrovirais apropriados para a gestação, utilizar a via de parto cesárea, utilizar TARV no pós-parto e para o bebê nas primeiras 6 semanas, suspender o aleitamento materno e utilizar fórmulas infantis, a fim de evitar o contato da criança com o vírus através das secreções maternas (RACHID, 2017).

As crianças que recebem diagnóstico do vírus HIV iniciam um tratamento muito complexo. A AF ainda não é bem difundida no Brasil, e isso traz consequências ao paciente que por muitas vezes recebe informações desencontradas e inadequadas sobre o tratamento, que necessitará de um acompanhamento multidisciplinar com farmacêutico, nutricionista, psicólogo e pediatra. (PEDROSO \& VITORINO, 2019)

Um estudo de 2012 avaliou a importância da atenção farmacêutica em pacientes pediátricos, e foi demonstrado que crianças que eram bem assistidas tinham um melhor desempenho no tratamento, tendo como resultado um aumento na porcentagem de adesão à TARV. (SANTANA et al, 2019) 
Soares (2017) relata em seu trabalho que é importante que o farmacêutico trace orientações claras e objetivas, relacionadas a condição patológica/fisiológica, afim de reduzir as reações adversas da TARV, e assim promovendo o bem-estar físico e psicológico do paciente.

Nas Unidades Dispensadoras de Medicamentos Antirretrovirais (UDM) há a presença de um farmacêutico que pode prestar um atendimento individualizado ou em coletividade, orientando sobre o HIV, o tratamento e os tipos de cuidados cruciais que devem ser tomados pelos pais e/ou responsáveis pela criança portadora da doença (VILLARINHO, 2013).

FIGURA 2 - Sequência da Atenção Farmacêutica de Pacientes Pediátricos com HIV

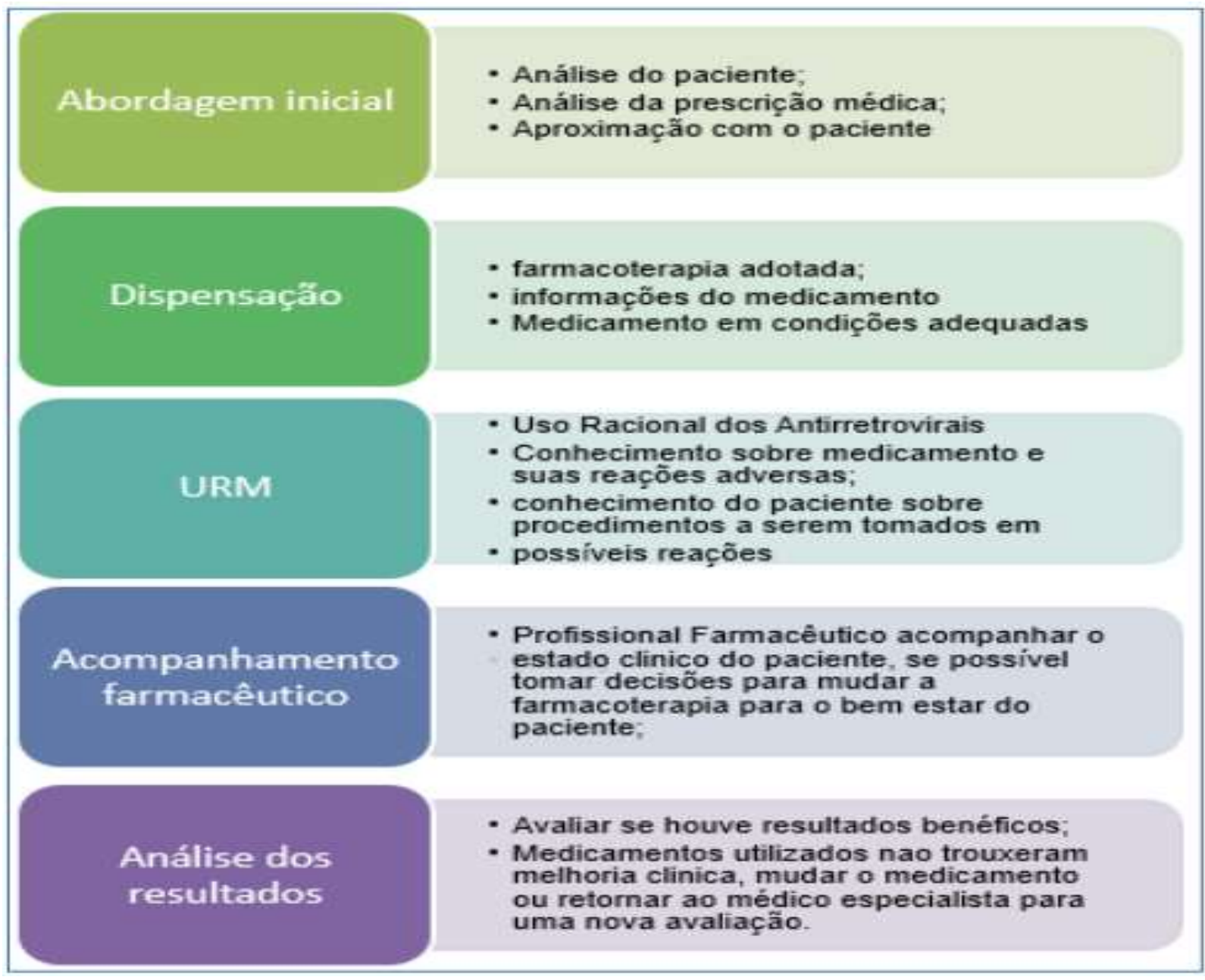

Fonte: Pedroso \& Vitorino, 2019 
5.5 DISPENSAÇÃO DE ANTI-RETROVIRAIS: COMO A ATENÇÃO FARMACÊUTICA PODE SER UTILIZADA COMO ESTRATÉGIA PARA ADESÃO AO TRATAMENTO E O USO RACIONAL DOS MEDICAMENTOS

O cuidado farmacêutico é considerado fundamental na adesão ao tratamento com antirretrovirais, a empatia na abordagem de um tratamento é capaz de desenvolver uma melhor relação entre usuário e o serviço de saúde. Já a baixa adesão ao tratamento reduz sua eficácia e traz complicações ao caso clínico do paciente. Se tratando de pacientes pediátricos, é de extrema importância que a TARV seja muito bem orientada aos pais e/ou responsáveis, pois o início do tratamento inclui não só a tomada do medicamento, como também a realização frequente de exames, o cuidado nutricional, hábitos de higiene adequados, o conhecimento sobre a doença e suas implicações na saúde e vida da criança e das pessoas que convivem com ela, consultas regulares e a busca do medicamento na farmácia, só com uma boa orientação a criança e seus responsáveis terão um assistência de qualidade, que influenciará positivamente, proporcionando um tratamento eficaz (VIELMO, 2013; FERREIRA, 2014).

É importante que a criança e os responsáveis sejam orientados por uma equipe multidisciplinar, composta por farmacêutico, nutricionista, médico, psicólogo, enfermeiro e serviço social, a fim de que cada profissional aborde a terapêutica que será realizada, através de uma linguagem que o paciente e seus cuidadores entendam, é também importante frisar que a equipe esteja disponível para acolher essas famílias emocionalmente fragilizadas. Pesquisas mostram que pacientes bem assistidos e que fazem uso de $95 \%$ das doses recomendas alcançam a efetividade na TARV, isso significa que a carga viral fica abaixo de 50 cópias virais $/ \mathrm{ml}$, tornando-se indetectável em exames laboratoriais (ARAUJO, et al 2017)

A liberação de medicamentos antirretrovirais é de uso restrito, para ter acesso ao tratamento, o responsável pela criança deve fazer o preenchimento de um formulário cedido pelo Ministério da Saúde, para isso o mesmo deve se dirigir a uma Unidade Dispensadora de Medicamento (UDM) do seu distrito. Emitido esse documento, é então liberado a retirada da TARV, seja na unidade de saúde municipal ou estadual. Algo que 
precisa ser melhorado é a dispensação de medicamentos para novos pacientes, pois as distribuições são feitas de modo que não interfira nas terapias que já tenham sido iniciadas, levando os novos pacientes a aguardarem novas distribuições para iniciarem a TARV, podendo haver um atraso de algumas semanas ao tratamento (BRASIL, 2018).

FIGURA 3 - Fluxo de liberação dos antirretrovirais de uso restrito

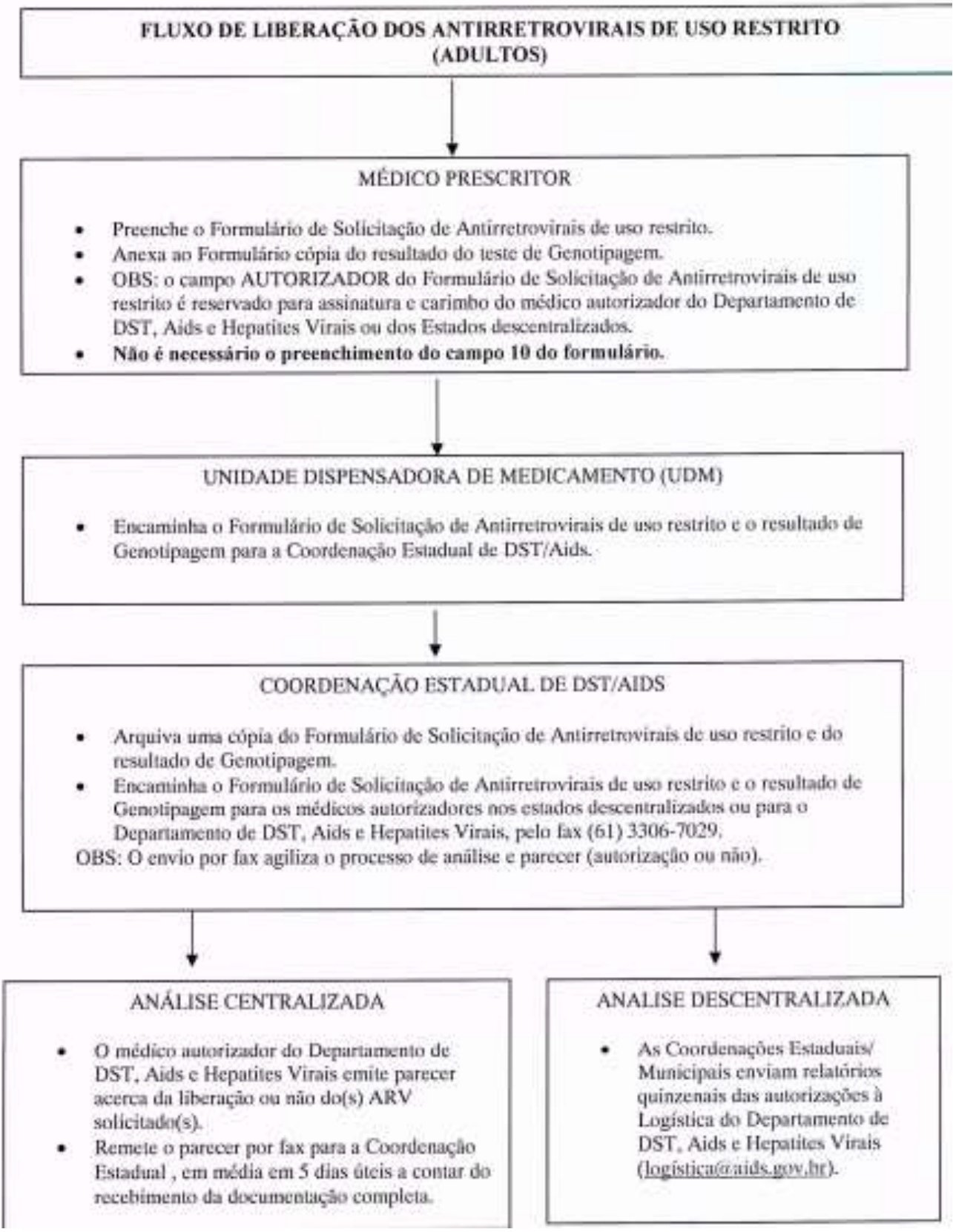

FONTE: Ministério da Saúde, 2018. 
O farmacêutico ao orientar sobre o uso racional de medicamentos no âmbito do Serviço Único de Saúde (SUS) deve focar em: garantir os padrões de qualidade do tratamento, ter boa interação entre paciente/profissional, assegurar o comprometimento com as questões sanitárias frente à população, dispor de um atendimento humanizado e individual se assim for solicitado pelo paciente, garantindo assim um atendimento decisivo e de grande relevância na evolução do prognóstico desses pacientes, evitando a evasão e piora dos quadros infecciosos provenientes de uma TARV irregular (RIBEIRO, 2017).

\subsection{TERAPIA ANTIRRETROVIRAL EM CRIANÇAS PORTADORAS DO VÍRUS HIV/AIDS}

A principal finalidade da TARV nos pacientes pediátricos é a imunossupressão e a cessação da replicação viral, assim sendo possível restabelecer e preservar a função imunológica, recuperar o crescimento, melhorar o desenvolvimento, reduzir a morbimortalidade, atrelando todos esses benefícios a uma melhor qualidade de vida da criança (MINISTÉRIO DA SAÚDE, 2009).

Alguns fatores limitantes da resposta à TARV em crianças são: falha na adesão estrita ao esquema de drogas antirretrovirais, toxicidade das drogas e efeitos adversos, imediatos e mediatos, uso prévio de antirretrovirais com falha e resistência viral, altos níveis de carga viral e baixa contagem de linfócitos $\mathrm{T} \mathrm{CD}_{4}+$ antes do tratamento, presença de comorbidades que limitem o uso de algumas drogas no esquema (e.g. tuberculose) e níveis séricos inadequados devido a aspectos de farmacocinética das drogas usadas, mudanças metabólicas (idade) e alterações relacionadas à requisição de administração com ou sem alimentos (MINISTÉRIO DA SAÚDE, 2009).

O monitoramento da resposta terapêutica à TARV deve ser realizado periodicamente, e tem o intuito de avaliar a adesão e tolerância ao tratamento, afecções relacionadas à síndrome de recuperação imunológica, efeitos adversos e a eficácia da TARV (CORREIA, 2018).

O sucesso terapêutico é caracterizado quando há máxima e sustentada supressão viral, ou seja, quando a carga viral se torna indetectável por muito tempo, em conjunto 
com a restauração da imunidade e ausência de sintomas relacionados à infecção por HIV/AIDS. É considerado indetectável o paciente pediátrico com queda de $>\mathrm{I}, \mathrm{o}$ log Io na carga viral após 8 a I2 semanas de tratamento, nos pacientes lactantes, essa fase indetectável pode demorar até 12 meses para ser diagnosticada (MINISTÉRIO DA SAÚDE, 2018).

Para informações sobre os medicamentos utilizados na TARV ver o ANEXO i ao final desse artigo.

\section{CONCLUSÃO}

Conclui-se através desse estudo que a atenção farmacêutica é uma ferramenta imprescindível na terapia de crianças portadoras do vírus HIV, sendo o profissional farmacêutico o que dispõe com mais propriedade de informações sobre o tratamento com drogas antirretrovirais, pois cabe a ele orientar, garantir e acompanhar o paciente portador de HIV/AIDS afim de que o mesmo tenha a saúde imunológica restaurada.

A atenção farmacêutica ainda é pouco difundida, são necessários que mais

profissionais estudem e coloquem em prática, consolidando os benefícios da mesma, facilitando a adesão medicamentosa dos pacientes, tendo como objetivo melhoria no tratamento e bem estar físico e psicológico das crianças soropositivas.

\section{REFERÊNCIAS BIBLIOGRÁFICAS}

ANGONESI D, Sevalho G. Atenção Farmacêutica: fundamentação conceitual e crítica para um modelo brasileiro. Ciência \& saúde coletiva. 2010. v. I5, p. 3603-3614

ARAUJO, Larissa Serafim et al. Diagnósticos de Enfermagem em Pessoas Vivendo com AIDS: uma Revisão Integrativa. In: Congresso Internacional de Enfermagem. 2017.

BRASIL. Ministério da Saúde. Secretaria de Vigilância em Saúde. Programa Nacional de DST e Aids. Protocolo para a prevenção de transmissão vertical de HIV e sífilis: manual de bolso. Ministério da Saúde, Secretaria de Vigilância em Saúde, Programa Nacional de DST e Aids. - Brasília: Ministério da Saúde, 2007

BRASIL. Ministério da Saúde. Secretaria de Vigilância em Saúde. Departamento de Vigilância, Prevenção e Controle das Infecções Sexualmente Transmissíveis, do HIV/Aids e das Hepatites Virais. Manual Técnico para o Diagnóstico da Infecção pelo HIV em Adultos e Crianças - Brasília: Ministério da Saúde, 2018 
BRASIL. Protocolo de assistência farmacêutica em DST/HIV/Aids: recomendações do Grupo de Trabalho de Assistência Farmacêutica Ministério da Saúde, Secretaria de Vigilância em Saúde, Departamento de DST, Aids e Hepatites Virais. - Brasília: Ministério da Saúde, 2010. p.93 .

CAETANO, Teidsonuarlei Fernandes; NETO, Orozimbo Henriques Campos. Atenção Farmacêutica Aos Portadores De Hiv/Aids No Sistema Único De Saúde (Sus). Rev Brasileira De Ciências Da Vida, v. 5, n. I, 2017

CORREIA MG. Cura do HIV: barreiras e perspectivas futuras. Instituto Universitário Egas Moniz, 2018.

FERREIRA B, Izar F, Lemos C, Ribas JLC. Antibióticos E Antirretrovirais: Uma Abordagem Biotecnológica. Rev. Saúde e Desenvolvimento. 2017; v. II, n.9, p.234-248

FERREIRA PM. HIV/Aids E O Farmacêutico No Serviço De Assistência Especializado Sae. 2014

FIOCRUZ. Aids: A doença / agentes causadores. 2013. Disponível em: https://agencia.fiocruz.br/aids. Acesso em: 22 de agosto de 2021.

MINISTÉRIO DA SAÚDE (BR). Secretaria de Vigilância em Saúde Departamento de DST, Aids e Hepatites Virais. Manual Técnico Para O Diagnóstico Da Infecção Pelo HIV. 2013

MINISTÉRIO DA SAÚDE (BR). Secretaria de Vigilância em Saúde Programa Nacional de DST e Aids. Recomendações para Terapia Antirretroviral em Crianças e Adolescentes Infectados pelo HIV. 2009. n. 85, p.83.

MINISTÉRIO DA SAÚDE. Protocolo Clínico e Diretrizes Terapêuticas para Manejo da Infecção pelo HIV em Crianças e Adolescentes. MANEJO DA INFECÇÃ̂O PELO HIV EM CRIANÇAS E ADOLESCENTES. Secretaria de Vigilância em Saúde. Departamento de DST, Aids e Hepatites Virais, 2018

PEDROSO WM, VITORINO KA. Atenção Farmacêutica no Tratamento de Crianças Portadoras Da Aids/Hiv. Rev da Faculdade de Educação e Meio Ambiente - FAEMA, 2019. v. Io, n. I, p. 34־43.

PEREIRA, Silvana Velho. Assistência ambulatorial e farmacêutica de serviço especializado em HIV/AIDS em município do sul do Brasil. 2012.

OLIVEROS, Marcia Perez Resende. Evolução das mutações de resistência aos inibidores de protease em pacientes infectados pelo HIV-I subtipo F. 2009. p. I29-129. Disponível em: https://pdfs.semanticscholar.org/ar85/4aacb463f7bao239ardre93596fd54a24e6o.pdf> Acesso em: 25 ago 202I

NUNES JÚNIOR, Sebastião Silveira; CIOSAK, Suely Itsuko. Terapia antirretroviral para HIV/AIDS: o estado da arte. Rev. enferm. UFPE, p. IIO3-IIII, 2018. Disponível em: https://periodicos.ufpe.br/revistas/revistaenfermagem/article/viewFile/231267/28690

Acesso em: 27 de agosto de 2021. 
PONTE AM. Evidencias Empírica de um modelo Teórico para explicar a Noopsicossomática em pessoas vivendo com HVI/AIDS. João Pessoa: Universidade Federal do Paraíba; 2012

RACHID M, Schechter M. Manual do HIV / Aids. Thieme Revinter Publicações LTDA, 2017.

RIBEIRO, Yaminny Aparecida Carvalho; NETO, Orozimbo Henriques Campos. Acompanhamento farmacoterapêutico de pacientes portadores de HIV/Aids. Rev Brasileira de Ciências da Vida, 2017, v. 5, n. I.

SANTANA JC, DA SILVA CP, PEREIRA CA. Principais Doenças Oportunistas Em Indivíduos Com HIV. Humanidades E Tecnologia (Finom) 2019. V. I, n. I6

SOARES, Letícia Santana da Silva. Construção de um modelo de avaliação do processo de assistência farmacêutica na atenção primária: uma ênfase ao processo de cuidado. 2017

TIMERMAN A, Magalhães N. Histórias da AIDS. Autêntica; 2015

UNAIDS - Folha de Dados 2021. ESTATÍSTICAS MUNDIAIS SOBRE O HIV. Disponível em: https://unaids.org.br/wpcontent/uploads/202I/06/2020_II_19_UNAIDS_FactSheet_PORT_Revisada-Final.pdf.

Acesso em: 2I de agosto de 202I.

VASCONCELOS SG. Repercussões Do Cotidiano De Famílias Com Crianças Nascidas Expostas Ao HIV. Fortaleza: Faculdade Federal Do Ceará; 2009.

VIELMO L. A Importância $\mathrm{Da}$ Atenção Farmacêutica $\mathrm{Na}$ Adesão A Terapia Antirretroviral No HIV/Aids. Rio Grande Do Sul: Universidade Federal De Santa Maria; 2013.

VIELMO L, Campos MMA, Beck ST, Andrade CS. Atenção farmacêutica na fase inicial de tratamento da AIDS como fator importante na adesão aos antirretrovirais. Rev. Bras Farm. 2014. v. 95, n. 2, p. 617-35.

VILLARINHO, Mariana Vieira et al. Políticas públicas de saúde face à epidemia da AIDS e a assistência às pessoas com a doença. Revista Brasileira de Enfermagem, v. 66, n. 2, p. 27I-277, 2013

WHERE DID HIV COME FROM? www.theaidsinstitute.org. 20II. Disponível em: https://www.theaidsinstitute.org/print/25. Acesso em: 2I de agosto de 2021.

ZANON BP, Almeida PB, Brum CN, de Paula CC, Padoin SMM, Quintana AM. Rev. bioét. 2016; v. 24, n. 3. P. 557-66 